\title{
Future Changes of a Slow-Moving Intense Typhoon with Global Warming: A Case Study Using a Regional 1-km-mesh Atmosphere-Ocean Coupled Model
}

\author{
Sachie Kanada ${ }^{1}$, Hidenori Aiki ${ }^{1,2}$, Kazuhisa Tsuboki ${ }^{1}$, and Izuru Takayabu ${ }^{3}$ \\ ${ }^{1}$ Institute for Space-Earth Environmental Research, Nagoya University, Nagoya, Japan \\ ${ }^{2} J a p a n$ Agency for Marine-Earth Science and Technology, Yokohama, Japan \\ ${ }^{3}$ Meteorological Research Institute, Tsukuba, Japan
}

\begin{abstract}
Numerical experiments on Typhoon Trami (2018) using a regional 1-km-mesh three-dimensional atmosphere-ocean coupled model in current and pseudo-global warming (PGW) climates were conducted to investigate future changes of a slow-moving intense typhoon under the warming climate. Over the warmer sea in the PGW climate, the maximum near-surface wind speed rapidly increased around the large eye of the simulated Trami. The stronger winds in the PGW simulation versus the current simulation caused a 1.5-fold larger decrease of sea surface temperature (SST) in the storm core-region. In the PGW climate, near-surface air temperature increased by $3.1^{\circ} \mathrm{C}$. A large SST decrease due to ocean upwelling caused downward heat fluxes from the atmosphere to the ocean. The magnitude of the SST decrease depended strongly on initial ocean conditions. Consideration of the SST decrease induced by an intense typhoon, and a slow-moving storm in particular, indicated that such a typhoon would not always become more intense under the warmer climate conditions. An atmosphere-ocean coupled model should facilitate making more reliable projections of typhoon intensities in a warming climate.

(Citation: Kanada, S., H. Aiki, K. Tsuboki, and I. Takayabu, 2021: Future changes of a slow-moving intense typhoon with global warming: A case study using a regional 1-km-mesh atmosphere-ocean coupled model. SOLA, 17A, 14-20, doi:10.2151/ sola.17A-003.)
\end{abstract}

\section{Introduction}

Intense tropical cyclones (TCs) have caused disastrous destruction in coastal regions (e.g., Jonkman et al. 2009; Mori et al. 2014; Takemi et al. 2019). The maximum potential intensity of a TC generally increases as sea surface temperature (SST) increases (e.g., DeMaria and Kaplan 1994; Emanuel 1988). The SST increase projected by most of state-of-the-art global climate models thus implies potential increases of TC intensity in a warming climate (e.g., IPCC 2012; Mizuta et al. 2014; Tsuboki et al. 2015; Yoshida et al. 2017). To prevent future disasters, it is essential to understand how warmer environmental conditions will change such intense TCs.

Intensification of TCs is closely related to the SST beneath the storm. Although the high sensible and latent heat fluxes associated with high SSTs enhance TC intensification (e.g., Emanuel 1986), concurrent thermal diffusion in the ocean mixed layer and upwelling stimulated by the strong near-surface winds associated with TCs decrease SST and suppress TC development (e.g., D'Asaro et al. 2014; Price 1981; Shay et al. 2000; Wada et al. 2014). The magnitude of the SST decrease induced by TCs depends on upperocean structure and the intensity and translation speed of the TC; intense TCs with slow translation speeds often cause a large SST decrease (e.g., Price et al. 1994; Lin et al. 2008, 2009).

The ocean mixed layer depth south of Japan decreases as latitude increases during the major typhoon season. Furthermore, the mixed layer depth is projected to decrease in a future warming climate (Huang et al. 2015). Thus, a future TC initially intensified by warmer SSTs could enhance subsequent reduction of SSTs when the storm travels over the sea south of Japan.

Cloud-resolving models with a horizontal resolution of less than $5 \mathrm{~km}$ should be used to represent the intensity and structure of TCs (e.g., Kanada and Wada 2016). Wu et al. (2016) also showed that use of a three-dimensional atmosphere-ocean coupled model was crucial for simulating the upper ocean response induced by Typhoon Megi (2010). However, most studies on TC intensity changes under a warming climate have used the results of atmosphere models or atmosphere-ocean coupled models with relatively coarse horizontal resolutions (e.g., Mizuta et al. 2017; Yoshida et al. 2017; Roberts et al. 2020).

The goal of the present study was to understand how an intense TC would change under warmer climate conditions when the response of the ocean to the storm was included in detail. For that purpose, simulations of typhoon Trami (2018) under warmer climate conditions were conducted using a regional 0.01-degreemesh three-dimensional atmosphere-ocean coupled model. The mesh size was roughly $1 \mathrm{~km}$. Trami was an intense typhoon with a slow translation speed and was expected to have large impacts of a SST change. Simulations of a slow-moving intense typhoon under warmer climate conditions using a regional three-dimensional atmosphere-ocean coupled model with a resolution sufficiently high to accurately represent the intensity and structure of TCs should facilitate projections of TC intensities in the future.

\section{Models and methodology}

The model used in the present study was a regional highresolution three-dimensional atmosphere-ocean coupled model composed of the Cloud Resolving Storm Simulator version 3.4 (CReSS; Tsuboki and Sakakibara 2002) for the atmospheric component and the Non-Hydrostatic Ocean model for the Earth Simulator (NHOES; Aiki et al. 2006, 2011) for the oceanic part. This coupled model has been referred to as the CReSS-NHOES (Aiki et al. 2015). The horizontal domain of the coupled model spanned $121^{\circ} \mathrm{E}-140.01^{\circ} \mathrm{E}$ and $14^{\circ} \mathrm{N}-33.01^{\circ} \mathrm{N}$ (Fig. 1), and it was discretized with a grid spacing of $0.01^{\circ}$ by $0.01^{\circ}$.

The procedure used to conduct the pseudo-global warming (PGW) simulations was similar to that of Kanada et al. (2019, 2017a, b). First, a control simulation of Typhoon Trami (2018) under current climate conditions was performed (the CNTL simulation). Initial and lateral boundary conditions for the atmospheric model were provided every $6 \mathrm{~h}$ from the Japan Meteorological Agency global objective analysis dataset with a horizontal resolution of $0.25^{\circ} \times 0.20^{\circ}$ (GANALjp; Japan Meteorological Agency 2013). Initial and lateral boundary conditions for the ocean model were provided every $24 \mathrm{~h}$ from the Japan Coastal Ocean Predictability Experiment reanalysis product (JCOPE2M, Miyazawa et al. 2017, 2019). Simulations started at 0600 UTC on 26 September 2018 and ended at 1800 UTC on 29 September 2018. During that time, the storm traveled over the ocean south of Japan at a slow translation speed and retained its central pressure of $\sim 950 \mathrm{hPa}$ as it subsequently passed over Okinawa Island (Figs. 1 and 2).

For the PGW simulations, we used the results of climate runs

Corresponding author: Sachie Kanada, Nagoya University, Furo-cho, Nagoya 464-8601, Japan. E-mail: skanada@nagoya-u.jp.

CThe Author(s) 2021. This is an open access article published by the Meteorological Society of Japan under a Creative Commons Attribution 4.0 International (CC BY 4.0) license (http://creativecommons.org/license/by/4.0). 

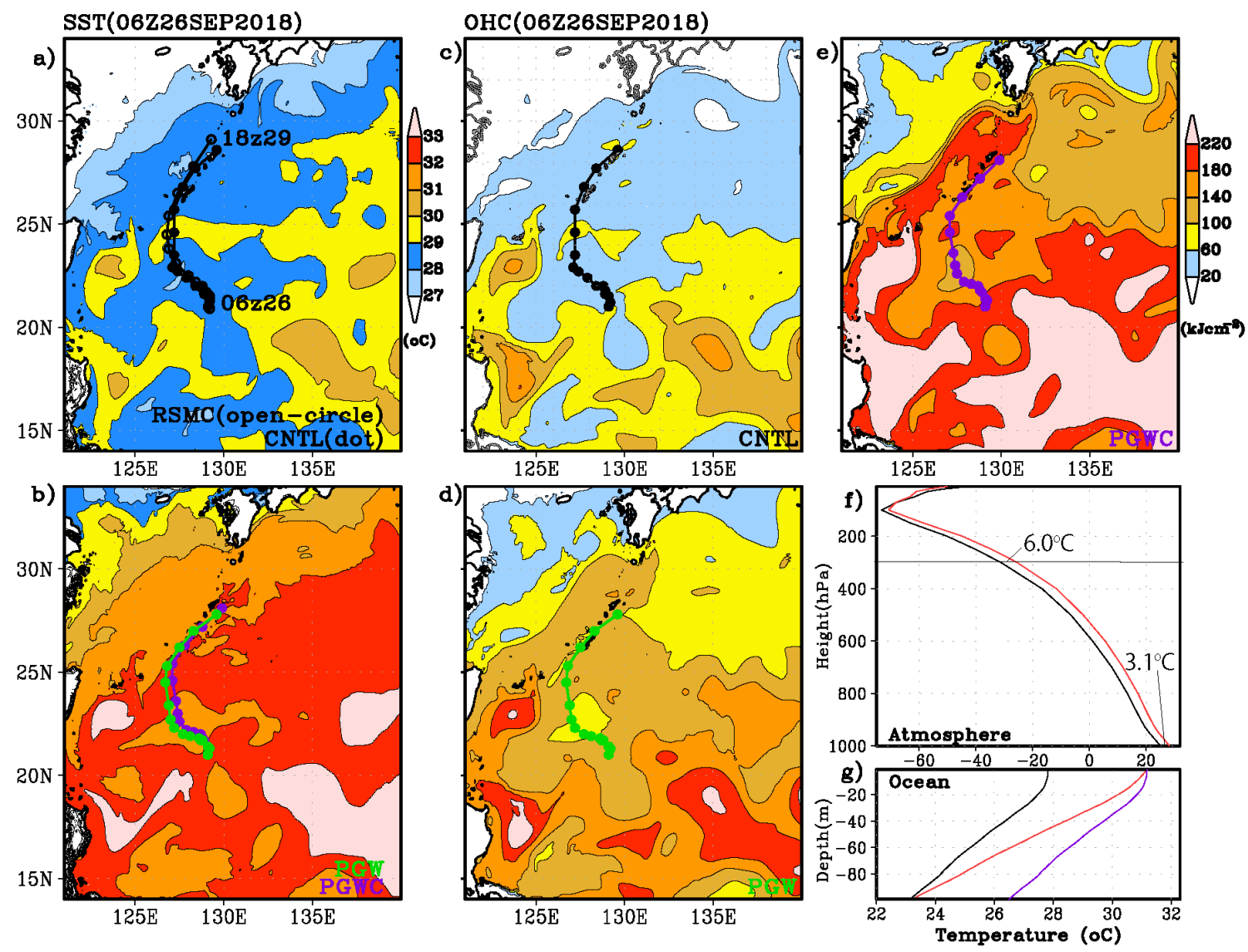

Fig. 1. Horizontal distributions of sea surface temperature (SST) in the (a) CNTL, and (b) PGW simulations and ocean heat content in the (c) CNTL, (d) PGW, and (e) PGWC simulations at 0600 UTC on 26 September 2018 with tracks of typhoon Trami (2018) at six-hour intervals from the RSMC besttrack (black line with open circles), the CNTL (black line with dots), PGW (green line), and PGWC (purple line) simulations. Mean profiles of (f) atmospheric temperature and (g) ocean temperature within $14^{\circ} \mathrm{N}-34^{\circ} \mathrm{N}, 122^{\circ} \mathrm{E}-134^{\circ} \mathrm{E}$ in the $\mathrm{CNTL}$ (black), PGW (red), and PGWC (purple) simulations.

by MRI-AGCM version 3.2 for 1979-2003 and 2075-2099 under the Representative Concentration Pathways (RCP) 8.5 scenario (Mizuta et al. 2012, 2014). Monthly mean climate values for September in the current run were subtracted from those in the RCP8.5 scenario run. In the PGW simulation, the increments were averaged in the simulated domain and added to the initial and boundary conditions of the CNTL simulation.

For the ocean model, SST increments were added to ocean temperature (Tocean) from the sea surface to a depth of $100 \mathrm{~m}$. The increments decreased linearly to zero at $100 \mathrm{~m}$ (red line in Fig. 1g) because Huang et al. (2015) have reported that the vertical temperature gradient will be steeper in a warming climate. To understand the sensitivity of the ocean initial conditions to TC intensity, we performed another PGW simulation (the PGWC simulation) with different ocean boundary conditions: constant SST increments were added to all $\mathrm{T}_{\text {ocean }}$ from the surface to a depth of $100 \mathrm{~m}$ (purple line in Fig. 1g). Table 1 lists the experiments. Supplement 1 provides more detailed information about the models, data, and the PGW method.

\section{Results}

Figure 1 shows the track of Typhoon Trami (2018) at six-hour intervals during the simulation with the initial oceanic and atmospheric conditions. During the first day of the simulation, the storm traveled to the northwest at very low speeds of $0.5-2.1 \mathrm{~m} \mathrm{~s}^{-1}$ according to the Regional Specialized Meteorological Center Tokyo (hereafter, RSMC) Best Track dataset (http://www.jma. go.jp/jma/jma-eng/jma-center/rsmc-hp-pub-eg/besttrack.html). The SST along the track exceeded $28^{\circ} \mathrm{C}$ (Fig. 1a), but the ocean
Table 1. List of experiments with the initial and boundary conditions used in the simulations.

\begin{tabular}{cll}
\hline Exp.name & \multicolumn{1}{c}{ Atmosphere } & \multicolumn{1}{c}{ Ocean } \\
\hline CNTL & GANALjp & JCOPE2M \\
PGW & $\begin{array}{l}\text { GANALjp with } \\
\text { RCP8.5 increments }\end{array}$ & $\begin{array}{l}\text { JCOPE2M with RCP8.5 increments } \\
\text { (dSST decrease as depth increases) }\end{array}$ \\
PGWC & Same as PGW & $\begin{array}{l}\text { Same as PGW but a constant dSST } \\
\text { was added as depth increases }\end{array}$ \\
\hline
\end{tabular}

heat content (OHC; Lin et al. 2008) was generally smaller than 60 $\mathrm{kJ} \mathrm{cm}^{-2}$. In the PGW simulation, the SST and $\mathrm{OHC}$ in most places exceeded $30^{\circ} \mathrm{C}_{\text {and }} 100 \mathrm{~kJ} \mathrm{~cm}^{-2}$ (Fig. 1b). The OHC in the PGWC simulation with a warmer subsurface ocean was considerably larger, $140 \mathrm{~kJ} \mathrm{~cm}^{-2}$ (Fig. 1e).

Mean air temperatures in the warming climate simulation were higher throughout the troposphere. The temperature increase in the lower troposphere was $3.1^{\circ} \mathrm{C}$ and reached a maximum of $6.0^{\circ} \mathrm{C}$ at an altitude of $300 \mathrm{hPa}$ (Fig. 1f). Atmospheric conditions thus stabilized in the warming climate simulation, and that stability presumably had negative effects on TC development (e.g., Hibino et al. 2018; Hill and Lackmann 2011). The mean water vapor mixing ratio in the lower troposphere increased by $3.5 \mathrm{~g} \mathrm{~kg}^{-1}$ in the warming climate simulation (not shown).

The CNTL simulation reproduced the track of Typhoon Trami (2018) (Fig. 1a). The storms in the PGW and PGWC simulations followed almost the same track as the CNTL storm, although the translation speeds were slightly smaller in the former two simulations than in the CNTL simulation (Fig. 1b). Because the major 


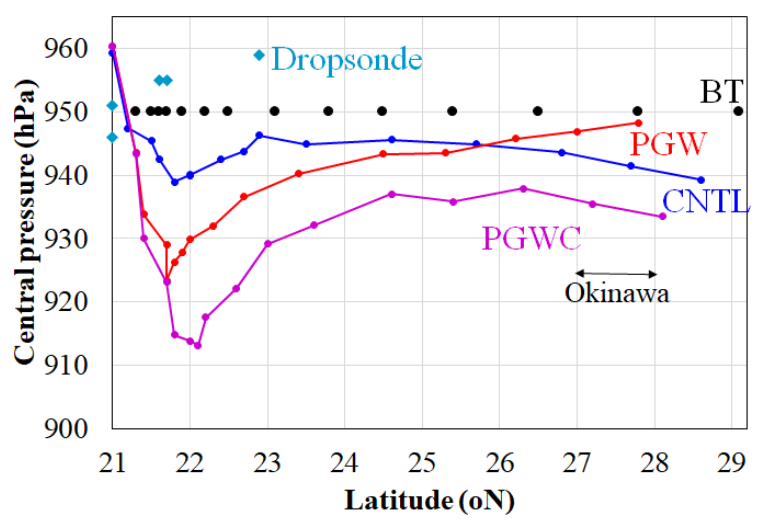

Fig. 2. Temporal evolutions of central pressure at the latitude of the storm center in the CNTL (blue line), PGW (red line), and PGWC (purple line) simulations. Black dots indicate central pressure of the RSMC besttrack at six-hour intervals. Cyan asterisks indicate central pressures from dropsonde data during aircraft missions of the Tropical cyclones-Pacific Asian Research Campaign for Improvement of Intensity estimations/forecasts (T-PARCII).

goal of the present study was to elucidate the relationship between the evolution of TCs and the changes of SST distributions induced by TCs in a warming climate, we compared the temporal evolutions of the TCs as a function of the latitudes of the storm centers (Fig. 2). Although the besttrack showed a constant central pressure of $950 \mathrm{hPa}$ throughout the simulation period, dropsonde observations revealed that the storm weakened between $21^{\circ} \mathrm{N}$ and $23^{\circ} \mathrm{N}$. The CNTL simulation overestimated the storm intensity, but the increase of the simulated central pressure between $22^{\circ} \mathrm{N}$ and $23^{\circ} \mathrm{N}$ was consistent with observations. In the PGW simulations, the simulated storm intensified rapidly at the beginning of the simulation. However, development of the TCs ceased when the storms entered regions with relatively low SSTs and OHCs at around $22^{\circ} \mathrm{N}$ (Fig. 1). The central pressures of the storms in the CNTL and PGW simulations were almost identical when they passed over Okinawa Island $\left(26^{\circ} \mathrm{N}-27^{\circ} \mathrm{N}\right)$.

High SSTs generally have a positive effect on TC development, whereas strong winds around a storm eye cause a large SST decrease. We investigated the horizontal distributions of hourly precipitation, $10-\mathrm{m}$ wind speeds, and SST around the storm center at 0000 UTC on 28 September 2018, when the storm centers were located between $22^{\circ} \mathrm{N}$ and $23^{\circ} \mathrm{N}$ (Fig. 3). Typhoon Trami (2018) was characterized by a large eye with a diameter of about $150 \mathrm{~km}$ (Fig. 3j). According to the RSMC and Joint Typhoon Warning Center (JTWC; https://www.metoc.navy.mil/jtwc/jtwc.html) best track datasets, the maximum near-surface wind speeds (Vmax) were $44 \mathrm{~m} \mathrm{~s}^{-1}$ (RSMC) and $46 \mathrm{~m} \mathrm{~s}^{-1}$ (JTWC) and the radius of the maximum wind speed (RMW) was $74 \mathrm{~km}$ (JTWC). The CNTL simulation captured those characteristics; Vmax and RMW of the storm in the CNTL simulation were $45 \mathrm{~m} \mathrm{~s}^{-1}$ and $76 \mathrm{~km}$, respectively (Fig. 3). The SST dropped to $23^{\circ} \mathrm{C}$ within a region of strong winds on the eastern side of the inner core (Fig. $3 \mathrm{~g}$ ). The inner core was defined by the region within $200 \mathrm{~km}$ of the storm's center (Rogers et al. 2013; Yoshida et al. 2017).

Vertical turbulent mixing and ocean upwelling are significant under a TC with a slow translation speed (e.g., Lin et al. 2009; Price et al. 1994), and there was a significant SST decrease of $7^{\circ} \mathrm{C}$ under Typhoon Megi (2010), which had a translation speed of $2.7 \mathrm{~m} \mathrm{~s}^{-1}$ in the South China Sea (D'Asaro et al. 2014). Translation speeds of the simulated Trami were generally slower than $3.0 \mathrm{~m} \mathrm{~s}^{-1}$ between 0600 UTC on 26 September to 0600 UTC on 28 September 2018. The considerable slow translation speed of Trami likely explains the substantial SST decrease.
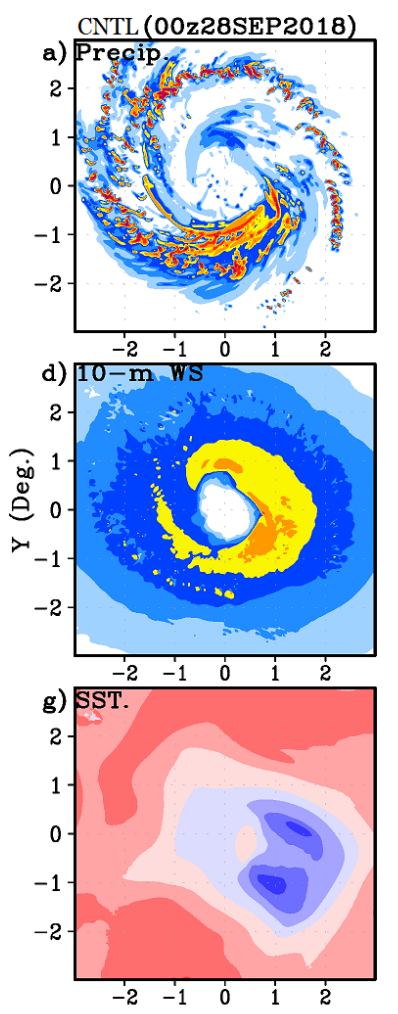
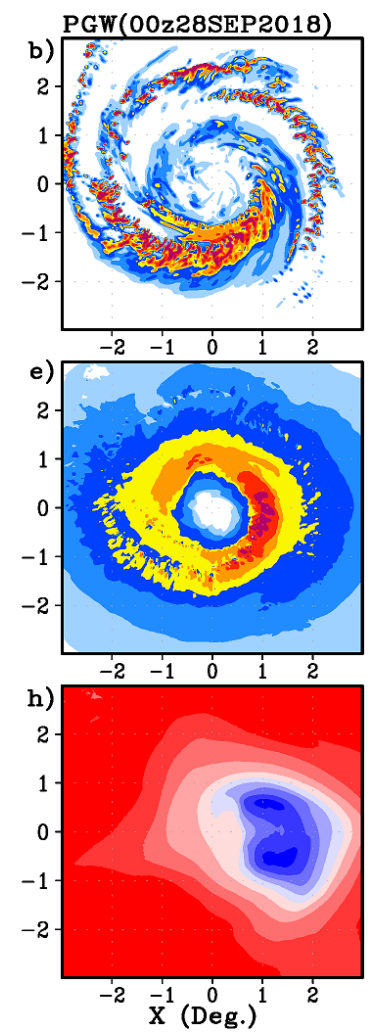
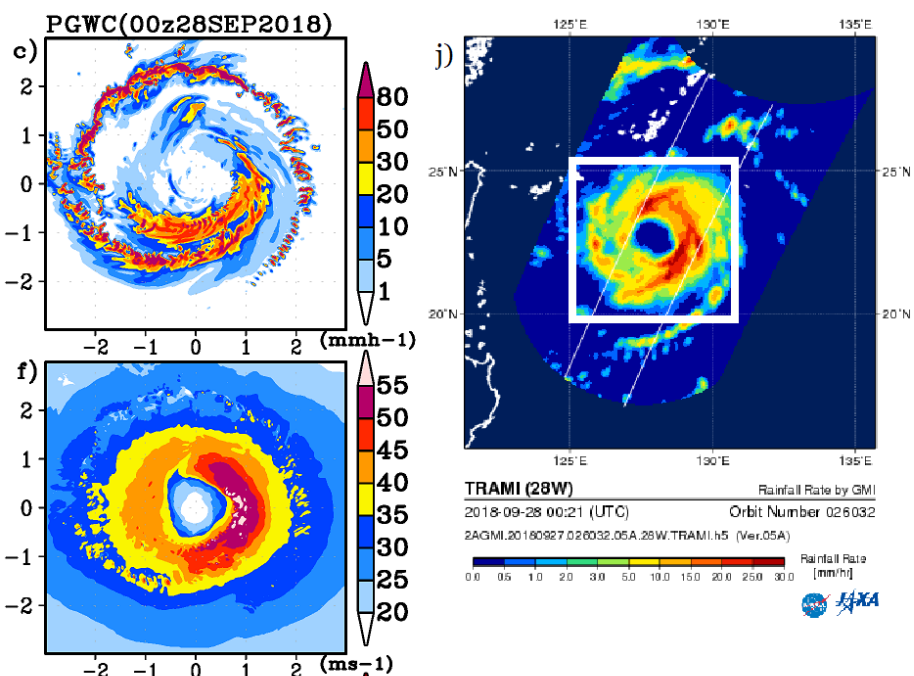

-

Fig. 3. Storm-centered horizontal distributions of hourly precipitation in the (a) CNTL, (b) PGW, and (c) PGWC simulations at 0000 UTC on 28 September 2018. (d)-(f): Same as (a)-(c), but for 10-m wind speed. (g)-(i): Same as (a)-(c), but for SST. (j) Rain images via Global Precipitation Measurement at 0021 UTC on 28 September 2018 by the Japan Aerospace eXploration Agency. The images can be accessed online at https://sharaku.eorc.jaxa.jp/TYP_DB/ index_e.html. 

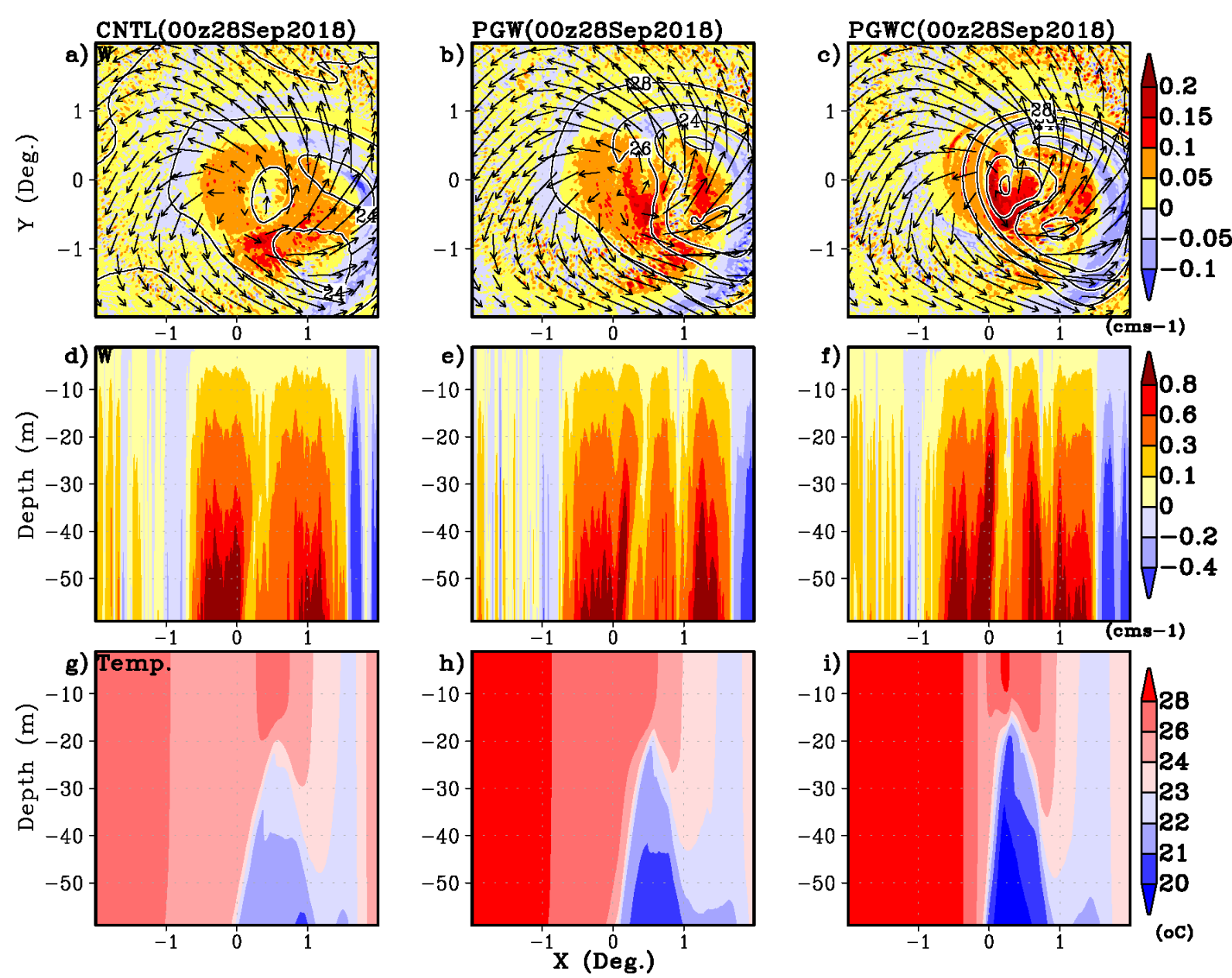

Fig. 4. Storm-centered horizontal distributions of ocean vertical velocity at a 5-m depth intervals in the (a) CNTL, (b) PGW, and (c) PGWC simulations at 0000 UTC on 28 September 2018. Arrows and contours indicate horizontal motion and ocean temperature at the same depth. Longitudinal cross sections of ocean vertical velocity across the storm center in the (d) CNTL, (e) PGW, and (f) PGWC simulations at 0000 UTC on 28 September 2018. (g)-(i): Same as (d)-(f), but for ocean temperature.

Figure 4 shows the three-dimensional structure of the ocean beneath the storm inner core. Regions with upward velocities greater than $0.05 \mathrm{~cm} \mathrm{~s}^{-1}$ appeared under the region of the core where the ocean temperature decreased (Fig. 4a). Longitudinal cross sections across the storm center indicated that water temperatures were low in regions characterized by strong upward motion (Figs. 4d and 4g).

In the PGW and PGWC simulations, Vmax increased to $54 \mathrm{~m} \mathrm{~s}^{-1}$ and $59 \mathrm{~m} \mathrm{~s}^{-1}$, respectively. Stronger winds can induce larger SST decreases. In fact, the storms in both the PGW and PGWC simulations caused stronger upward motion with lower ocean temperatures than the CNTL simulation (Fig. 4). The SSTs to the east of the storm center dropped below $22^{\circ} \mathrm{C}$ in both warming simulations (Figs. $3 \mathrm{~h}$ and $3 \mathrm{i}$ ). The SSTs around the storm center, which are crucial for TC development (Kanada et al. $2017 \mathrm{c}$ ), therefore decreased by as much as $\sim 9^{\circ} \mathrm{C}$ in the PGW simulations, compared with the result of the CNTL simulation.

The mean temperature in the lower troposphere increased by $3.1^{\circ} \mathrm{C}$ in the warming simulations (Fig. 1f). The warming in the lower troposphere and the large SST decrease resulted in large downward sensible and latent heat fluxes from the atmosphere to the sea in the warming climate simulations (Fig. 5). The SSTs around the storm core were initially much higher in the warming simulations than in the CNTL simulation (Figs. 1 and 6). However, strong winds caused the mean SST in the PGW simulation to decrease rapidly to $27^{\circ} \mathrm{C}$ at $22^{\circ} \mathrm{N}$ latitude (Fig. 6a). The mean SST decrease in the inner core was enhanced 1.5-fold in the PGW versus CNTL simulations, and the difference between the mean
SSTs in the PGW and CNTL simulations decreased to $1{ }^{\circ} \mathrm{C}$. In the warming simulations, there was consequently less heat flux from the ocean to the storm boundary layer, and there was actually an influx of heat from the warmer atmosphere to the ocean at $\sim 22^{\circ} \mathrm{N}$ at 0000 UTC on 28 September 2018 (Figs. 5 and 6). Thus, the storm in the PGW simulation lost the advantage of warmer sea under the warmer climate conditions (Figs. 1 and 2).

\section{Discussion: Impacts of upper-ocean conditions}

The magnitude of sea surface cooling induced by TCs is closely related to upper-ocean conditions (e.g., Price 1981; Lin et al. 2008). In the present study, the horizontal distributions of SST in the PGW and PGWC simulations were the same (Fig. 1b), but the OHC was substantially larger in the latter (Fig. 1e) than in the former (Fig. 1d). At the beginning of the simulation, the PGWC storm developed rapidly. Whereas the PGW storm ceased developing after attaining a minimum pressure of $923 \mathrm{hPa}$ at $21.7^{\circ} \mathrm{N}$, the PGWC storm continued developing, and its central pressure reached a minimum of $913 \mathrm{hPa}$ at $22.1^{\circ} \mathrm{N}$ (Fig. 2). The wind speeds around the eye of the TC were $5 \mathrm{~m} \mathrm{~s}^{-1}$ faster in the PGWC versus PGW simulations, and they exceeded $55 \mathrm{~m} \mathrm{~s}^{-1}$ in the former (Figs. 3e and 3f). The local SST decrease (Fig. 3i) associated with the cold upwelling (Figs. 4f and 4i) was large due to the stronger winds, but the decrease was limited to a small area (Figs. 5c and 5f). The mean SST in the storm inner core was thus warmer in the PGWC than in the PGW simulation (Fig. 6a) 

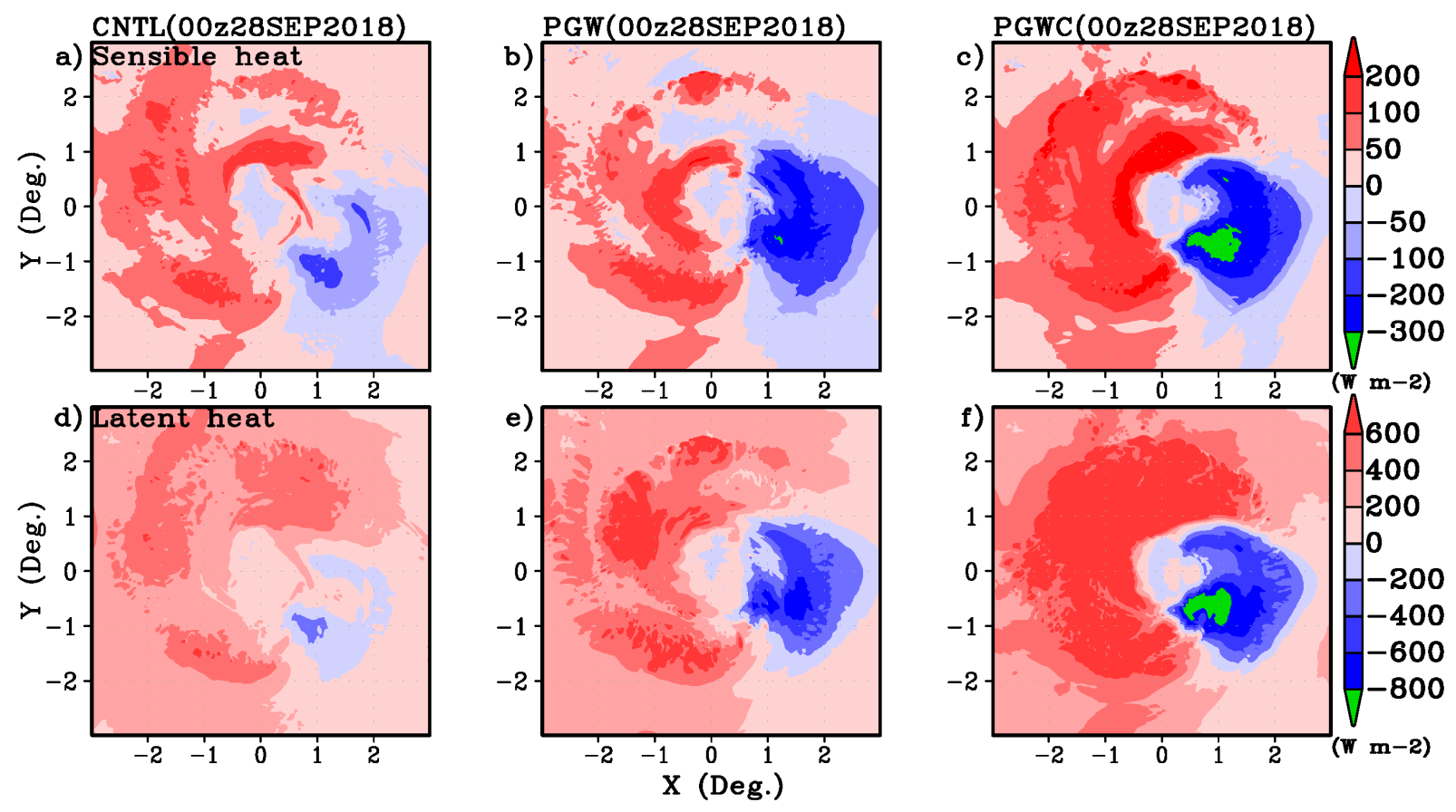

Fig. 5. Same as Fig. 3, but for (a)-(c) sensible heat flux $\left(\mathrm{W} \mathrm{m}^{-2}\right)$ and (d)-(f) latent heat flux $\left(\mathrm{W} \mathrm{m}^{-2}\right)$.
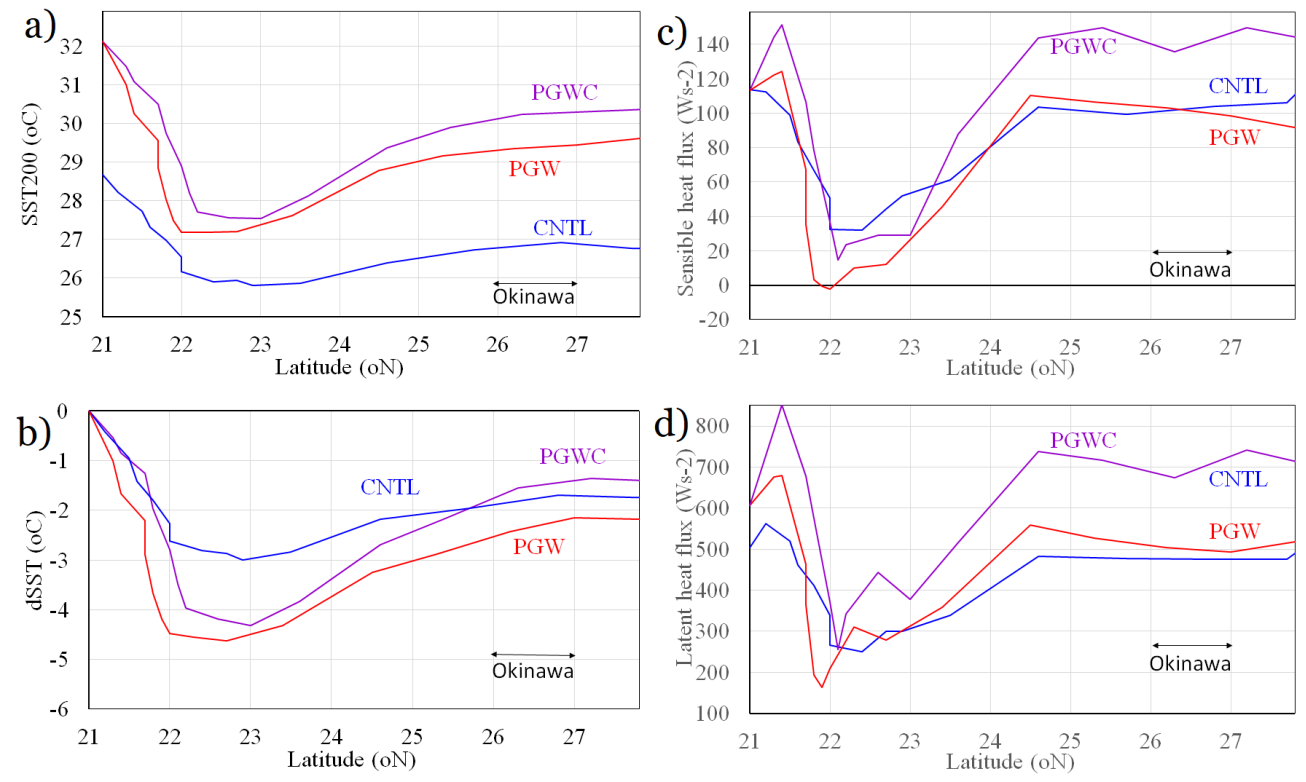

Fig. 6. Temporal evolutions of (a) mean SST $\left({ }^{\circ} \mathrm{C}\right)$, (b) mean SST decrease $\left({ }^{\circ} \mathrm{C}\right)$, (c) mean sensible heat flux $\left(\mathrm{W} \mathrm{m}^{-2}\right)$, and $(\mathrm{d})$ mean latent heat flux $\left(\mathrm{W} \mathrm{m}^{-2}\right)$ of the storm inner-core relative to the latitude of the storm center in the CNTL (black line), PGW (red line), and PGWC (purple line) simulations. The inner core was defined by the region within $200 \mathrm{~km}$ of the storm's center.

because in the former case the mean SST decrease of the inner core was suppressed by the large OHC (Fig. 6b). Furthermore, the $\mathrm{SST}$ in the eye was as high as $28^{\circ} \mathrm{C}$. A high SST in the eye can facilitate eyewall convection and help TC intensification (Kanada et al. 2017c). As a result, the central pressures were always $\sim 10$ hPa lower in the PGWC than in the PGW simulation. The maximum latent heat flux of $800 \mathrm{~W} \mathrm{~m}^{-2}$ in the PGWC simulation corresponded to a decrease of the temperature of the upper $1 \mathrm{~m}$ of the water column by less than $1^{\circ} \mathrm{C}$ per hour. The results therefore indicated that upwelling, which can only be simulated with a three-dimensional ocean model, was the main cause of the SST decrease.

\section{Summary}

Future changes of typhoon intensity over the sea south of Japan under a warmer climate scenario were investigated using results of the climate change experiments on Typhoon Trami (2018) by a regional 1-km-mesh three-dimensional atmosphere-ocean coupled model. Typhoon Trami (2018) was selected to investigate the impact of a SST decrease induced by a typhoon in current and PGW climates because it was an intense typhoon with a slow translation speed.

Over the warmer sea in the PGW climate, the simulated Trami 
rapidly increased the maximum near-surface wind speed around its large eye. However, the stronger winds caused a SST decrease of $4.5^{\circ} \mathrm{C}$ below the storm core and thereby suppressed the development of the storm. The larger SST decrease and the warmer atmosphere in the warming climate resulted in downward heat fluxes from the atmosphere to the ocean. As a result, the intensity of the simulated Trami in the warming climate could not increase when the storm arrived at Okinawa Island. The results indicated that a slow-moving intense typhoon in a PGW climate would not always become more intense if consideration was given to the SST decrease induced by the storm. Sensitivity experiments on initial ocean conditions showed a large impact on storm intensity; a larger ocean heat content led to a stronger storm, even if the storm developed stronger near-surface winds.

It should be noted that the PGW simulations in the present study were conducted on a typhoon using the RCP8.5 increments and two ocean increment profiles. Further studies on TCs with different characteristics using several atmosphere and ocean increments should be required to deepen our knowledge on future changes in TCs under the warming climate. Nevertheless, the results of the present study demonstrated that the magnitude of SST decreases induced by a TC was a key factor for the storm intensity and hence the intensity was strongly affected by the initial ocean conditions. Studies by a high-resolution atmosphere-ocean coupled models and more reliable projections of both atmospheric and oceanic conditions should therefore be used to lessen the uncertainty associated with future projections of typhoons that could be a threat to midlatitude coastal regions.

\section{Acknowledgements}

The authors are grateful to two reviewers and an editor for instructive comments. This work was supported by the Integrated Research Program for Advancing Climate Models (TOUGOU) Grant Number JPMXD0717935561 from the Ministry of Education, Culture, Sports, Science and Technology (MEXT), Japan, and by the Japan Society for the Promotion of Science (JSPS) KAKENHI grant number 26400466. The dropsonde data were obtained via aircraft missions of the T-PARCII supported by JSPS KAKENHI grant number JP16H06311. Numerical simulations were performed using the Earth Simulator at Japan Agency for Marine-Earth Science and Technology (JAMSTEC).

Edited by: T. Nakaegawa

\section{Supplement}

Supplement 1 provides detailed information about the models and methodology.

\section{References}

Aiki, H., K. Takahashi, and T. Yamagata, 2006: The Red Sea outflow regulated by the Indian Monsoon. Cont. Shelf Res., 26, $1448-1468$.

Aiki, H., J. P. Matthews, and K. G. Lamb, 2011: Modeling and energetics of tidally generated wave trains in the Lombok Strait: Impact of the Indonesian Throughflow. J. Geophys. Res., 116, C03023, doi:10.1029/2010JC006589.

Aiki, H., M. Yoshioka, M. Kato, A. Morimoto, T. Shinoda, and K. Tsuboki, 2015: A coupled atmosphere-ocean-surface-wave modeling system for understanding air-sea interactions under tropical cyclone conditions. Bull. Coastal Oceanogr., 52, 139-148.

D'Asaro, E., and co-authors, 2014: Impact of typhoons on the ocean in the Pacific: ITOP. Bull. Amer. Meteor. Soc., 95, 1405-1418.

DeMaria, M., and J. Kaplan, 1994: Sea surface temperature and the maximum intensity of Atlantic tropical cyclones. $J$.
Climate, 7, 1324-1334.

Emanuel, K. A., 1988: The maximum intensity of hurricanes. $J$. Atmos. Sci., 45, 1143-1155.

Emanuel, K. A., 1986: An air-sea interaction theory for tropical cyclones. Part I: Steady-state maintenance. J. Atmos. Sci., 43, 585-605.

Hibino, K., I. Takayabu, Y. Wakazuki, and T. Ogata, 2018: Physical responses of convective heavy rainfall to future warming condition: Case study of the Hiroshima event. Front. Earth Sci., 6, 35, doi:10.3389/feart.2018.00035.

Hill, K. A., and G. M. Lackmann, 2011: The impact of future climate change on TC intensity and structure: A downscaling approach. J. Climate, 24, 4644-4661, doi:10.1175/2011 JCLI3761.1.

Huang, P., I.-I. Lin, C. Chou, and R.-H. Huang, 2015: Changes in ocean subsurface environment to suppress tropical cyclone intensification under global warming. Nat. Commun., 6, 7188, doi:10.1038/ncomms8188.

IPCC, 2012: Managing the risks of extreme events and disasters to advance climate change adaptation. A Special Report of Working Groups I and II of the Intergovernmental Panel on Climate Change. C. B. Field, V. Barros, T. F. Stocker, D. Qin, D. J. Dokken, K. L. Ebi, M. D. Mastrandrea, K. J. Mach, G.-K. Plattner, S. K. Allen, M. Tignor, and P. M. Midgley, Eds., Cambridge University Press, Cambridge, UK, and New York, NY, USA, 582 pp.

Japan Meteorological Agency, 2013: Outline of the operational numerical weather prediction at the Japan Meteorological Agency (Available online at: http://www.jma.go.jp/jma/jmaeng/jma-center/nwp/outline2013-nwp/index.htm, accessed 28 September 2020).

Jonkman, S. N., B. Maaskant, E. Boyd, and M. L. Levitan, 2009: Loss of life caused by the flooding of New Orleans after Hurricane Katrina: Analysis of the relationship between flood characteristics and mortality. Risk Analysis, 29, 676698.

Kanada, S., and A. Wada, 2016: Sensitivity to horizontal resolution of the simulated intensifying rate and inner-core structure of typhoon Ida, an extremely intense typhoon. $J$. Meteor. Soc. Japan, 94A, 181-190, doi:10.2151/jmsj.2015037.

Kanada, S., K. Tsuboki, and I. Takayabu, 2019: Future changes in typhoon-related precipitation in eastern Hokkaido. SOLA, 15, 244-249, doi:10.2151/sola.2019-044.

Kanada, S., K. Tsuboki, H. Aiki, S. Tsujino, and I. Takayabu, 2017a: Future enhancement of heavy rainfall events associated with a typhoon in the midlatitude regions. SOLA, 13, 246-251, doi:10.2151/sola.2017-045.

Kanada, S., T. Takemi, M. Kato, S. Yamasaki, H. Fudeyasu, K. Tsuboki, O. Arakawa, and I. Takayabu, 2017b: A multimodel intercomparison of an intense typhoon in future, warmer climates by four 5-km-mesh models. J. Climate, 24, 6017-6036, doi:10.1175/JCLI-D-16-0715.1.

Kanada, S., S. Tsujino, H. Aiki, M. K. Yoshioka, Y. Miyazawa, K. Tsuboki, and I. Takayabu, 2017c: Impacts of SST patterns on rapid intensification of Typhoon Megi (2010). J. Geophys. Res., 122, 13245-13262, doi:10.1002/2017JD027252.

Lin, I. I., C. C. Wu, I. F. Pun, and D. S. Ko, 2008: Upper-ocean thermal structure and the western North Pacific category 5 typhoons. Part I: Ocean features and the category 5 typhoons' intensification. Mon. Wea. Rev., 136, 3288-3306.

Lin, I. I., I. F. Pun, and C. C. Wu, 2009: Upper ocean thermal structure and the western North Pacific category-5 typhoons. Part II: Dependence on translation speed. Mon. Wea. Rev., 137, 3744-3757.

Miyazawa, Y., A. Kuwano-Yoshida, T. Doi, H. Nishikawa, T. Narazaki, T. Fukuoka, and K. Sato, 2019: Temperature profiling measurements by sea turtles improve ocean state estimation in the Kuroshio-Oyashio Confluence region. Ocean Dyn., 69, 267-282.

Miyazawa, Y., S. M. Varlamov, T. Miyama, X. Guo, T. Hihara, K. Kiyomatsu, M. Kachi, Y. Kurihara, and H. Murakami, 2017: 
Assimilation of high-resolution sea surface temperature data into an operational nowcast/forecast system around Japan using a multi-scale three dimensional variational scheme. Ocean Dyn., 67, 713-728.

Mizuta, R., H. Yoshimura, H. Murakami, M. Matsueda, H. Endo, T. Ose, K. Kamiguchi, M. Hosaka, M. Sugi, S. Yukimoto, S. Kusunoki, and A. Kitoh, 2012: Climate simulations using MRI-AGCM3.2 with $20-\mathrm{km}$ grid. J. Meteor. Soc. Japan, 90A, 233-258, doi:10.2151/jmsj.2012-A12.

Mizuta, R., O. Arakawa, T. Ose, S. Kusunoki, H. Endo, and A. Kitoh, 2014: Classification of CMIP5 future climate responses by the tropical sea surface temperature changes. SOLA, 10, 167-171, doi:10.2151/sola.2014-035.

Mizuta, R., and co-authors, 2017: Over 5000 Years of ensemble future climate simulations by $60 \mathrm{~km}$ global and $20 \mathrm{~km}$ regional atmospheric models. Bull. Amer. Meteor. Soc., 13831398, doi:10.1175/BAMS-D-16-0099.1.

Mori, N., M. Kato, S. Kim, H. Mase, Y. Shibutani, T. Takemi, K. Tsuboki, and T. Yasuda, 2014: Local amplification of storm surge by Super Typhoon Haiyan in Leyte Gulf. Geophys. Res. Lett., 41, 5106-5113, doi:10.1002/2014GL060689.

Price, J. F., 1981: Upper ocean response to a hurricane. J. Phys. Oceanogr., 11, 153-175.

Price, J. F., T. B. Sanford, and G. Z. Forristall, 1994: Forced stage response to a moving hurricane. J. Phys. Oceanogr., 24, 233-260.

Roberts, M. J., J. Camp, J. Seddon, P. L. Vidale, K. Hodges, B. Vannière, and co-authors, 2020: Projected future changes in tropical cyclones using the CMIP6 HighResMIP multimodel ensemble. Geophys. Res. Lett., 47, e2020GL088662, doi:10.1029/2020GL088662.

Rogers, R. F., P. Reasor, and S. Lorsolo, 2013: Airborne Doppler observations of the inner-core structural differences between intensifying and steady-state tropical cyclones. Mon. Wea. Rev., 141, 2970-2991.
Shay, L. K., G. J. Goni, and P. G. Black, 2000: Role of a warm ocean feature on Hurricane Opal. Mon. Wea. Rev., 128, 1366-1383.

Takemi, T., T. Yoshida, S. Yamasaki, and K. Hase, 2019: Quantitative estimation of strong winds in an urban district during Typhoon Jebi (2018) by merging mesoscale meteorological and large-eddy simulations. SOLA, 15, 22-27, doi:10.2151/ sola.2019-005.

Tsuboki, K., and A. Sakakibara, 2002: Large-scale parallel computing of Cloud Resolving Storm Simulator. High Performance Computing, H. P. Zima et al., Eds., 243-259, Springer, New York.

Tsuboki, K., M. K. Yoshioka, T. Shinoda, M. Kato, S. Kanada, and A. Kitoh, 2015: Future increase of supertyphoon intensity associated with climate change. Geophys. Res. Lett., 42, 646-652, doi:10.1002/2014GL061793.

Wada, A., T. Uehara, and S. Ishizaki, 2014: Typhoon-induced sea surface cooling during the 2011 and 2012 typhoon seasons: Observational evidence and numerical investigations of the sea surface cooling effect using typhoon simulations. Progress in Earth and Planetary Science, 1, doi:10.1186/21974284-1-11.

Wu, C.-C., W.-T. Tu, I.-F. Pun, I-I. Lin, and M. S. Peng, 2016: Tropical cyclone-ocean interaction in Typhoon Megi (2010) - A synergy study based on ITOP observations and atmosphere-ocean coupled model simulations. J. Geophys. Res., 121, 153-167, doi:10.1002/2015JD024198.

Yoshida, K., M. Sugi, R. Mizuta, H. Murakami, and M. Ishii, 2017: Future changes in tropical cyclone activity in highresolution large-ensemble simulations. Geophys. Res. Lett., 44, 9910-9917.

Manuscript received 28 September 2020, accepted 19 November 2020 SOLA: https://www.jstage.jst.go.jp/browse/solal 